\title{
Cigarette advertising and promotional strategies in retail outlets: results of a statewide survey in California
}

\author{
Ellen C Feighery, Kurt M Ribisl, Nina Schleicher, Rebecca E Lee, Sonia Halvorson
}

Stanford University School of Medicine, Stanford Center for Research in Disease Prevention, Palo Alto, California, USA

E C Feighery

N C Schleicher

R E Lee

S Halvorson

Department of Health Behavior and Health Education, School of Public Health,

University of North

Carolina at Chapel

Hill, Chapel Hill,

North Carolina, USA

K M Ribisl

Correspondence to:

Ellen Feighery, Stanford

Center for Research in

Disease Prevention, Stanford

University School of

Medicine, 1000 Welch Road,

Palo Alto, CA 94304-1885,

USA

feighery@scrdp.stanford.edu

Received 27 April 2000 and in revised form

9 September 2000.

Accepted 16 January 2001

\begin{abstract}
Objective-To examine the extent and types of cigarette advertising materials in stores and to assess tobacco company compliance with the 1998 Master Settlement Agreement (MSA).

Design-A cross-sectional analysis of a random sample of 586 stores that sold cigarettes.

Setting- US state of California.

Main outcome measures-Trained data collectors classified cigarette advertising materials by type (signs, displays, functional items), location (interior or exterior), and placement (below 3 feet (1 m) or near candy).

Results-California retail outlets featured 17.2 (SD 16.1) tobacco advertising materials on average, and $94 \%$ of stores featured at least some advertising. About $85 \%$ of these were within 4 feet $(1.3 \mathrm{~m})$ of the counter. About $50 \%$ of the stores had ads at or below 3 feet, and $23 \%$ had cigarette product displays next to candy. In violation of the MSA, $3 \%$ of stores featured signs with cartoons and $11 \%$ had large exterior signs.

Conclusions-Tobacco companies are aggressively using stores to market cigarettes. Moreover, the spirit of the MSA-to protect children from cigarette advertising-has not been realised. Future studies should monitor industry use of this venue and assess the impact of exposure to cigarette advertising materials in stores on adult smokers and youth. (Tobacco Control 2001;10:184-188)
\end{abstract}

Keywords: advertising; point-of-sale advertising; tobacco industry

Tobacco companies spend more money on the retail outlet than any other advertising venue. ${ }^{1}$ In contrast, tobacco companies spend relatively little on traditional print venues such as newspaper and magazine advertising. Retail outlet or point-of-purchase (POP) spending includes slotting fees, promotional allowances, and other POP marketing programmes. Since 1985, POP marketing expenditures have been the number one spending category for tobacco companies and each year POP spending has surpassed the amount spent on either print or outdoor advertising. Since then, both the amounts and proportion of money spent on POP marketing have increased dramatically, from $\$ 692$ million (28\% of total spending) in 1985 to $\$ 3.9$ billion (47\%) in 1999 . By 1997 , print and outdoor categories accounted for only $11 \%$ of the $\$ 8.2$ billion advertising budget. ${ }^{1}$

Recent efforts to restrict tobacco product advertising have focused largely on more traditional venues, such as magazines and billboards, while the retail outlet virtually has been ignored. The Master Settlement Agreement (MSA) between the state attorney generals and the tobacco companies aimed to prevent youth smoking by limiting tobacco sponsorships and promotional activities, and banning tobacco billboards. ${ }^{2}$ Two provisions directly affected advertising in retail outlets: a limit on the size of exterior signs to no more than 14 square feet ( 1.3 square metres), and a ban on the use of cartoons in all advertising. ${ }^{2}$ The proposed Food and Drug Administration (FDA) regulations on the marketing of tobacco products would have been more stringent because they mandated black and white, text only advertisements at retail outlets and banned self-service cigarette displays. ${ }^{3}$ However, the US Supreme Court ruled that the FDA did not have the authority to regulate tobacco products. ${ }^{4}$

Tobacco company in-store advertising materials may serve many of the traditional functions of advertising, such as increasing smokers' daily consumption by cueing smokers to light up or buy cigarettes, reducing current smokers' resolve to quit or consider quitting, and encouraging former smokers to resume their habit by reminding them of their favourite brand every time they visit a store. ${ }^{5}$ These advertising messages are all conveniently delivered in the same place where customers can readily purchase a pack of cigarettes. $^{6}$ Moreover, POP ads and displays have been found to boost average tobacco sales by $12 \%{ }^{7}$ to $28 \%{ }^{8}$

Retail outlet advertising, like other forms of advertising, may also entice children and young adults to begin smoking. ${ }^{5}$ Cigarette advertising has been related to increased uptake and maintenance of smoking among adolescents. ${ }^{9-12}$ Few studies have examined the extent and impact of youth exposure to tobacco ads in retail outlets. However, because three out of four teenagers shop at a convenience store at least once a week, ${ }^{8}$ many teens are exposed routinely to retail outlet tobacco advertising messages. In fact, a high percentage of seventh grade (12-13 year old) students $(62 \%)$ recall seeing cigarette advertising in retail outlets. ${ }^{13}$ Furthermore, children 
who report seeing cigarette advertising in retail outlets were $38 \%$ more likely to have experimented with smoking. ${ }^{13}$

Despite the vast amount of spending at retail outlets and its strategic importance to the tobacco companies, few studies have examined tobacco advertising in retail outlets. Earlier studies of 23 outlets in San Diego, California, and 61 in Buffalo, New York, found that stores featured substantial amounts of tobacco advertising and product displays. ${ }^{14}{ }^{15}$ In 1995, a convenience sample of 5700 retail outlets was surveyed by volunteers as part of the California Operation Storefront campaign to raise awareness about tobacco advertising in stores. Tobacco POP advertising and promotions were found next to candy and at the eye level of young children. ${ }^{16}$ In a study of tobacco advertising within 1000 feet $(300 \mathrm{~m})$ of schools in six Boston, Massachusetts neighbourhoods, $92 \%$ of 580 outdoor advertisements were at retail outlets. ${ }^{17}$ These studies have helped raise awareness about retail outlet advertising strategies, but were limited because either they were conducted in a single city, had small sample sizes, or non-random sampling of stores.

Because of the magnitude of tobacco industry expenditures in retail outlets and the limited research in this area, we conducted a study in a representative sample of California stores that sell cigarettes to: (1) examine the quantity and types of advertising materials used by tobacco companies to advertise cigarettes; (2) assess the amount of tobacco advertising by store type; (3) assess compliance with the MSA provisions that ban large exterior cigarette advertisements and the use of cartoons in any advertising; and (4) examine the placement of cigarette advertising materials in locations where children would be more

Table 1 Types and definitions of advertising materials collected at stores

\begin{tabular}{|c|c|c|}
\hline & Measure & Definition \\
\hline \multirow[t]{4}{*}{ 1) Type of material } & & \\
\hline & Signs & $\begin{array}{l}\text { Number of signs that are posters, banners or lighted } \\
\text { signs made by a cigarette manufacturer that are not part } \\
\text { of other existing items such as displays or overhead bins. } \\
\text { Categorised by size including }<\text { or } \geqslant 14 \text { square feet to } \\
\text { determine compliance with Master Settlement } \\
\text { Agreement provisions to limit size to } 14 \text { square feet }\end{array}$ \\
\hline & Displays & $\begin{array}{l}\text { Number of displays with brand specific advertising } \\
\text { including freestanding racks provided by the } \\
\text { manufacturer for the display of cigarette products and } \\
\text { plexi-glass enclosed packs of cigarettes that are visible } \\
\text { but inaccessible to consumers and clerks. }\end{array}$ \\
\hline & $\begin{array}{l}\text { Functional } \\
\text { items }\end{array}$ & $\begin{array}{l}\text { Number of brand specific items that have utility (for } \\
\text { example, branded shopping baskets, clocks, and } \\
\text { overhead bins) }\end{array}$ \\
\hline \multirow[t]{3}{*}{ 2) Location } & & \\
\hline & Exterior & $\begin{array}{l}\text { Number of materials located on the outside of the store } \\
\text { including on windows, doors, the building and sidewalk, } \\
\text { or in the parking lot. Signs posted on the inside of the } \\
\text { store, but facing outside were counted as exterior. }\end{array}$ \\
\hline & Interior & $\begin{array}{l}\text { Number of materials located inside the store including } \\
\text { those attached to window or door excluding those } \\
\text { facing outside. Recorded as "near" if on, behind, or } \\
\text { within } 4 \text { feet of the counter/checkout area, or "far" if } \\
\text { more than } 4 \text { feet away from counter/checkout area }\end{array}$ \\
\hline \multirow{3}{*}{ 3) Placement } & & \\
\hline & Below 3 feet & $\begin{array}{l}\text { Presence or absence of advertising materials at or below } \\
3 \text { feet from the floor }\end{array}$ \\
\hline & Next to candy & $\begin{array}{l}\text { Presence or absence of displays within } 6 \text { inches of candy } \\
\text { (sweets) }\end{array}$ \\
\hline
\end{tabular}

likely to be exposed to them such as near the counter, near candy, and at eye level of small children.

\section{Methods}

SAMPLE

As part of an earlier study conducted in 1997, a random sample of 700 California stores that sold cigarettes was identified from a comprehensive list of 40186 retail outlets maintained by the California Board of Equalization for taxation purposes. In March 1999, telephone verification confirmed that 626 stores $(89.4 \%)$ were still in business and sold cigarettes. Trained data collectors then visited all 626 stores and completed 590 surveys (four stores did not sell cigarettes, seven were partially completed, 10 were denied by the store owner or clerk, 11 stores were out of business when visited, and four stores were not found).

\section{MEASURES}

Stores were classified into one of seven categories: (1) convenience stores, including those that sell gas (petrol); (2) gas (petrol) stations, with no convenience store; (3) large drug stores (pharmacies), with at least three cash registers; (4) large markets, with at least three cash registers; (5) liquor stores; (6) small stores, including small drug stores and markets; and (7) tobacco stores (discount cigarette outlets and/or cigar/pipe stores). Store type also served as a proxy for store size.

Coders attended one and a half days of classroom instruction and an additional half day of in-store supervised training to learn the protocols for recording cigarette advertising materials. Staff coded each material along three dimensions: (1) type of material; (2) location of material; and (3) presence or absence of materials that might be more visible to children. These dimensions are defined in table 1 .

Compliance with the MSA was measured by identifying exterior signs larger than 14 square feet, or signs with cartoons. Cartoons were defined in accordance with section II (1) of the MSA: cartoons are defined as having comically exaggerated features, attribute human characteristics to animals or inanimate objects, or may attribute superhuman characteristics to figures (human or otherwise). ${ }^{2}$ To measure children's potential exposure to cigarette advertising, the existence of any advertising materials at or below 3 feet $(1 \mathrm{~m})$ from the floor and placement of displays within six inches $(0.17 \mathrm{~m})$ of candy was noted.

Interrater reliability was assessed in a random sample of 53 stores (9\% overlap), whereby two coders independently collected data on each store. Pearson correlation coefficients were computed to measure reliability for the number of advertising materials: interior signs $(r=0.77)$; exterior signs $(r=0.88)$; plexi-glass enclosures $(r=0.64)$; displays $(r=0.73)$; and functional items $(r=0.68)$. Reliability for the two dichotomously scored items was assessed using Cohen's $\kappa$ : existence of signs at or below 3 feet 


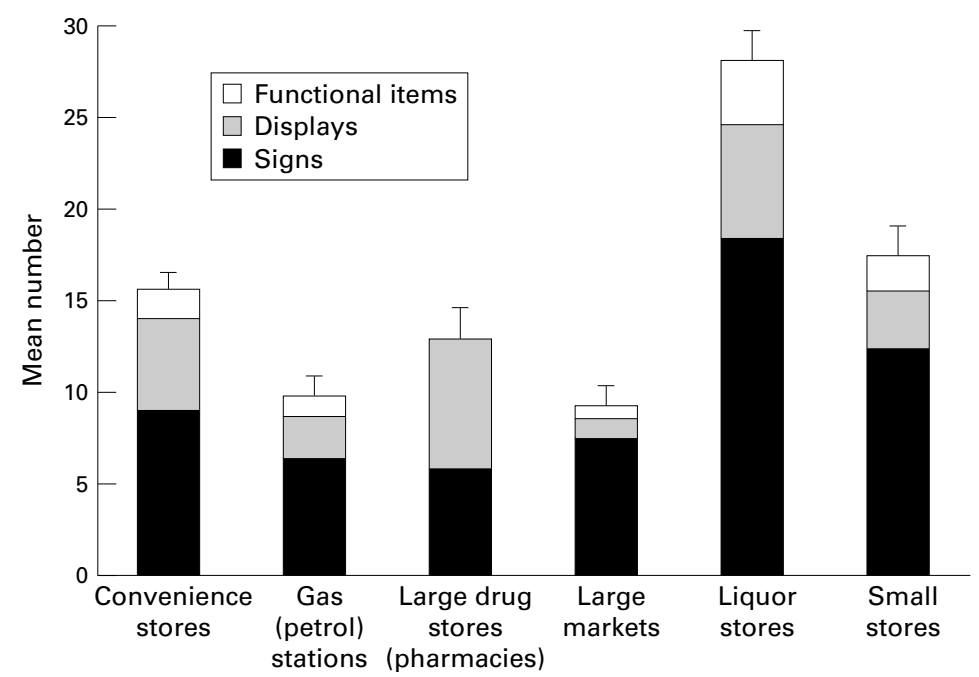

Figure 1 Tobacco retail marketing material by store type. Functional items: items with cigarette advertising that serve an additional purpose (for example, an ashtray or a clock). Displays: racks provided by the manufacturer for the display and sale of packs of cigarettes, generally with brand specific advertising and plexi-glass enclosed packs of cigarettes that are visible but inaccessible for purchase. Signs: posters made by a cigarette manufacturer and not part of other existing items. Error bars represent upper bound 95\% confidence interval.

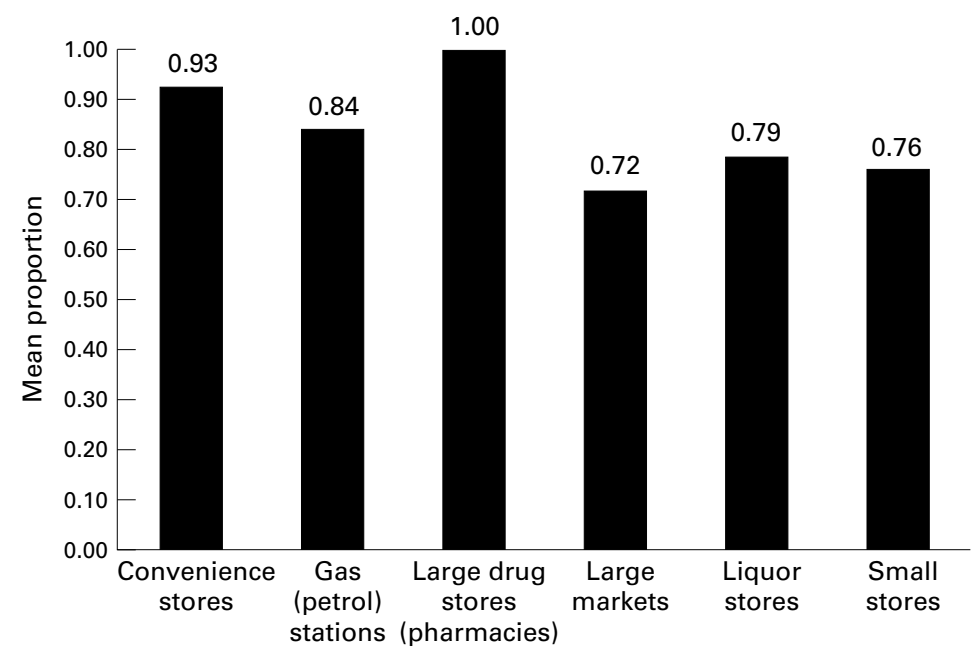

Figure 2 Proportion of interior tobacco retail marketing material within 4 feet $(1.3 \mathrm{~m})$ of the counter by store type. Stores without interior tobacco retail marketing materials were excluded $(n=49)$.

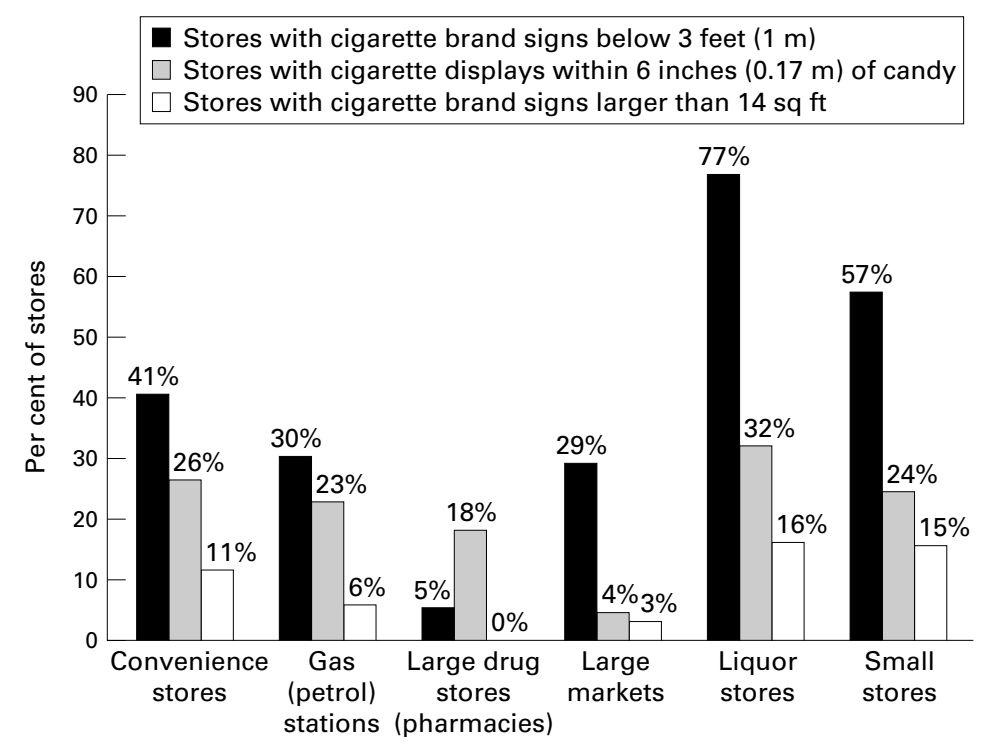

Figure 3 Percentage of stores with cigarette advertising materials easily visible to children. from the floor had fair agreement beyond chance $(\kappa=0.41)$, and for displays within 6 inches of candy agreement beyond chance was poor $(\kappa=0.27) .^{18}$

\section{DATA ANALYSIS}

Descriptive statistics were computed to characterise the quantity and nature of cigarette retail advertising and advertising materials in different types of stores. Appropriate measures of central tendency (mean), precision (95\% confidence interval (CI)), and sample variability (SD) were employed. Tobacco stores $(n=4)$ were removed from all analyses because of their small sample size. All analyses were performed using SPSS version $6.1 .^{19}$

\section{Results}

The average retail outlet in California $(n=586)$ featured a total of 17.2 cigarette advertising and promotional materials. Specifically, these retail outlets contained an average (SD) of: 3.6 (5.0) exterior signs, 7.5 (8.9) interior signs, 3.3 (4.0) cigarette displays, 0.9 (1.8) plexi-glass enclosed packs, and 1.7 (2.0) functional items. Figure 1 shows how the mean number of advertising materials per store varies among the different store types. Liquor stores had the greatest number of total advertising materials of any store type, followed by small stores and convenience stores. In addition, liquor stores had more signs and functional items than other store types. Large drug stores had more displays than any other store type, averaging 6.8 per store, more than double the overall mean number of displays. Ninety four per cent of all stores had at least one cigarette advertising material.

Figure 2 illustrates that the vast majority $(83 \%)$ of cigarette retail advertising materials that appeared within 4 feet $(1.3 \mathrm{~m})$ of the counter for all store types. In large drug stores, all materials were within 4 feet of the counter.

Figure 3 presents the proportion of stores that potentially expose children to cigarette advertising material by featuring interior signs at or below 3 feet, or locating displays within 6 inches of candy. Almost half of all stores had cigarette signage at or below 3 feet $(48 \%)$. These signs were most prevalent in liquor stores $(77 \%)$, followed by small stores $(57 \%)$. Drug stores rarely had signs at or below 3 feet $(5 \%)$. Displays placed next to candy were found most often in liquor stores (32\%). Approximately a quarter of convenience stores $(26 \%)$ and small stores (24\%) had cigarette displays placed within 6 inches of candy. Only $3 \%(\mathrm{n}=17)$ of stores had signs with cartoons (data not shown). All signs with cartoons advertised the RJ Reynolds brand Joe Camel. Overall, $11 \%$ of stores were in violation of the MSA by displaying at least one exterior sign larger than 14 square feet. Liquor stores (16\%) and small stores $(15 \%)$ were most often in violation, followed by convenience stores (11\%). No large drug stores had exterior signs larger than 14 square feet. 


\section{Discussion}

The purpose of this study was to: (1) examine the amount and types of advertising in retail outlets; (2) assess the amount of cigarette advertising by store type; (3) assess compliance with the MSA provisions that ban large exterior cigarette advertisements and the use of cartoons; and (4) examine the placement of cigarette advertising materials in locations where children would be more likely to be exposed to them. The study results reported here portray a clear picture of the tobacco companies' use of retail space to advertise and promote their products by placing large numbers of signs, functional items, and displays in prominent locations. Although all types of retail outlets included in the survey contain advertising materials, liquor stores followed by small stores are by far the most heavily saturated with signs and functional items. Some might argue that advertising in liquor stores is not a problem since adults primarily shop there. However, when California eighth grade smokers were asked where they bought their last cigarettes, the highest proportion $(28 \%)$ responded "liquor stores". Another $26 \%$ identified small stores ${ }^{20}$ which had the second highest amount of cigarette advertising materials.

The checkout counter area is coveted by all manufacturers who compete to have their products displayed there. Therefore, it is the prime in-store location for the purposes of advertising and displaying cigarette products. Almost $85 \%$ of all cigarette signs and displays were located within 4 feet of the counter area. Given this saturation, it is virtually impossible for young and adult shoppers to avoid exposure to pro-smoking messages when buying their snacks, food, beverages, or gasoline.

Although large drug stores had fewer signs and no functional items, on average they exhibited twice the number of displays than other store types. Our surveyors reported anecdotally that displays were often located next to nicotine replacement products. This observation raises an interesting question: are cigarette companies placing displays here to encourage quitters to relapse or are the drug companies trying to encourage smokers to quit? Since both the pharmaceutical and tobacco industries are vying to sell their products to smokers, ${ }^{21}$ the proliferation of cigarette displays at drug stores is disturbing.

As mentioned earlier, the MSA contains two provisions that directly affect stores. We found that $3 \%$ of the stores had signs with Joe Camel cartoons. We also found that $11 \%$ of the stores had exterior signs that exceeded the MSA size limit of no more than 14 square feet. In the absence of data before the MSA, we do not know if these findings represent a decrease in the number of stores with cartoons or signage of this size. It is clear though that the spirit of the MSA is not being followed: almost half of all stores had ads that were at or below 3 feet and almost a quarter had cigarette product displays next to candy. These findings confirm the results of earlier studies. ${ }^{15} 16$ They also indicate
What is already known on this subject

Tobacco companies spend about half of their marketing dollars to advertise and promote their products in stores. Despite the vast amount of spending in retail outlets and its strategic importance to the tobacco companies, few studies have examined tobacco advertising in retail outlets. These studies have been limited because either they were conducted in a single city, or had small sample sizes or non-random sampling of stores.

\section{What this paper adds}

The results of this cross-sectional analysis of a random sample of 586 stores that sold cigarettes in California portray a clear picture of the tobacco companies' use of retail space to market cigarettes aggressively. Moreover, the spirit of the Master Settlement Agreement- to protect children from cigarette advertising-has not been realised.

that while tobacco companies may be following the specific provisions of the agreement, there appears to be blatant disregard for its intent to protect children from tobacco advertising.

This study is limited by its focus on stores in California. Tobacco company marketing strategies may differ in other states. There is some evidence that tobacco companies have more extensive retail advertising activities in states with higher tobacco taxes and state funded tobacco control programmes, such as California. ${ }^{22}$ The tobacco companies may be using ubiquitous retail outlet advertising to reach their customer base given that about $65 \%$ of California smokers attempted to quit smoking at least once in the previous year. ${ }^{23} \mathrm{~A}$ national study of stores is needed to identify regional or state differences among all types of tobacco products including cigarettes, smokeless tobacco, and cigars. In addition, the effects of exposure to tobacco advertising on children and adults should be investigated in order to assess what retail outlet advertising actually "buys" tobacco companies.

Although this study found that most stores contained generous amounts of cigarette advertising, it was impractical to obtain data on all types of advertising in stores so we were unable to determine what proportion consists of cigarette advertising. Secondly, while rigorous training yielded highly reliable measurement for nearly all variables, for one variable-placement of displays within six inches of candy-reliability was lower than desired. Future studies should incorporate other training methodologies to enhance reliability of the data.

The tobacco industry is spending the largest share of its marketing dollars at the retail outlet where it is relatively free of regulation. The recent MSA and state lawsuits against cigarette companies have reduced tobacco company use of several traditional advertising venues, such as billboards. As a result, the retail outlet has become a hot property for cigarette 
companies $^{24}$ and POP displays by cigarette companies have proliferated..$^{725}$ Increasingly, the retail outlet is an important communication channel for its advertising, not just a place to buy products. ${ }^{26}{ }^{27}$ The results of this study support this phenomenon. Clearly, the retail outlet should be monitored carefully to determine cigarette company advertising strategies. The placement of these materials near the counter, at or below 3 feet, and next to candy virtually ensures that all shoppers, including children, are exposed to a number of messages that promote smoking.

This study was made possible by funds received from the Tobacco Tax Health Protection Act of 1988 - Proposition 99 , Tobacco Tax Health Protection Act of 1988 - Proposition 99 through the California Department of Health Services unde contract 94-20967-A04. The authors wish to acknowledge June
Flora PhD and Lisa Henriksen PhD, both at the Stanford Flora PhD and Lisa Henriksen PhD, both at the Stanford
Center for Research in Disease Prevention, for their valuable Center for Research in Dise
feedback on this manuscript.

1 Federal Trade Commission, Report to congress for 1999 pursuant to the federal cigarette labeling and advertising act

2 Master Settlement Agreement. National Association of Attorneys General, 1998. http://www.naag.org/tobaccopublic/ library.cfn

3 Kessler D, Witt A, Barnett P, et al. The Food and Drug Administration's regulation of tobacco products. $N$ Engl $\mathscr{f}$ Med 1996;335988-94.

4 Tobacco Free Kids. The FDA rule to reduce tobacco use among kids, 2000. http://tobaccofreekids.org/reports/fda/

5 Warner KE. Selling smoke: cigarette advertising and public health. Washington, DC: American Public Health Association, 1986

6 Rogers T, Feighery EC, Tencati EM, et al. Community mobilization to reduce point-of-purchase advertising of tobacco products. Health Educ O 1995;22:427-42.

7 Anon. The 1999 annual report of the promotion industry, a PROMO magazine special report. Overland Park, Kansas: PROMO magazine special

8 Point of Purchase Advertising Institute. The point-ofpurchase advertising industry fact book. Englewood, New Jersey: The Point of Purchase Advertising Institute, 1992.

9 Aitken PP, Eadie DR. Reinforcing effects of cigarette advertising on underage smoking. Br f Addiction 1990;85:399412 .

10 Gilpin EA, Pierce JP. Trends in adolescent smoking initiation in the United States: is tobacco marketing an influence? Tobacco Control 1997;6:122-7.
11 Pierce JP, Gilpin E, Burns DM, et al. Does tobacco advertising target young people to start smoking? Evidence from California. $7 A M A$ 1991;266:3154-8.

12 US Department of Health and Human Services. Preventing tobacco use among young people. A report of the Surgeon General, 1994. Atlanta, Georgia: Public Health Service, Centers for Disease Control and Prevention, Office on Smoking and Health, 1994. (US Government Printing Office Publication No S/N 017-001-00491-0.)

13 Schooler C, Feighery E, Flora JA. Seventh graders' self-reported exposure to cigarette marketing and its relationship to their smoking behavior. Am $\mathcal{F}$ Public Health 1996;86:1216-21.

14 Wildey MB, Young RL, Elder JP, et al. Cigarette point-of-sale advertising in ethnic neighborhoods in San Diego, California. Health E Values 1992;16:23-8.

15 Cummings K, Sciandra R, Lawrence J. Tobacco advertising in retail stores. Public Health Reports 1991;106:570-5.

16 Roeseler A, Russell C, Rogers T, et al. Operation Storefront: youth against tobacco advertising and promotion. Phase I survey results. Sacramento, California: California Department of Health Services, 1995.

17 Pucci LG, Joseph HM, Jr, Siegel M. Outdoor tobacco advertising in six Boston neighborhoods: evaluating youth exposure. Am f Prev Med 1998;15:155-9.

18 Fleiss J. Statistical methods for rates and proportions, 2nd ed. New York: John Wiley \& Sons, 1981.

19 SPSS. SPSS for MacIntosh. Chicago, Illinois: SPSS, Inc, 1995.

20 Consortium IE. Final report of the independent evaluation of the California tobacco control prevention and education program: wave I data, 1996-1997. Rockville, Maryland: The Gallup Organization, 1998:61.

21 Warner K, Slade J, Sweanor DT. The emerging market for long-term nicotine maintenance. $\mathcal{F} A M A$ 1997;278:108792.

22 Chaloupka F, Slater S, Wakefield M. USA: price cuts and point of sale ads follow tax rise. Tobacco Control 1999;8:242-6.

23 Pierce JP, Gilpin EA, Emery SL, et al. Tobacco control in California: who's winning the war? An evaluation of the tobacco control program, 1989-1996. La Jolla, California: University of California, San Diego, 1998.

24 Segal D. Philip Morris, Leader of the Packs. In: Washington Post, 15 September 1999, p E01

25 Wakefield MA, Terry YM, Chaloupka FJ, et al. Changes at the point-of-sale for tobacco following the 1999 tobacco billboard ban. Chicago: University of Illinois at Chicago. Research paper, Series 4.2000, p 17.

26 Borden T. Despite landmark settlement, new front opens in tobacco wars. In: Tribune-Review, Pittsburgh, 1999. http:// www.tribunereview.com

27 Pollack J. BE'W's Carlton relaunch first since new ad rules. In Advertising Age, 1 March 1999, New York, p 12. 